\title{
Ejes estratégicos en una política de seguridad
}

CIENCIA Y TECNOLOGÍA (CT) entrevista a la socióloga Julieta Castellanos, Socióloga hondureña, profesora titular de la Escuela de Sociología de la Facultad de Ciencias Sociales y Directora del recién creado Instituto Democracia, Paz y Seguridad (IUDPAS); es estudiosa de diversos temas de la realidad nacional, particularmente de temas de violencia, seguridad y partidos políticos, ha sido investigadora asociada del Centro de Documentación de Honduras (CEDOH) y ha publicado diversos libros y artículos sobre esos temas.

CT/ La entrevista la vamos a desarrollar alrededor de cuatro ejes: 1) conceptualización de la seguridad, 2) causas de la delincuencia y la violencia, 3) prevención vrs control y 4) niveles nacional y municipal. Comenzaremos entonces hablando del concepto de seguridad: Seguridad humana, seguridad ciudadana... ¿qué nos dice de eso?

$\mathrm{JC} /$ El concepto de seguridad ha ido creciendo e incorporando elementos que no solamente incluyen la seguridad física, que es la forma más visible de la inseguridad, y que las personas más valoran y sienten con cercanía o con distancia, y también incluye otros componentes de la seguridad: La seguridad alimentaria, la seguridad ambiental, que cobra mucha relevancia sobre todo en países altamente vulnerables. En ciudades como Tegucigalpa el tema de la vulnerabilidad ambiental toca directamente la seguridad de las personas, la seguridad de las viviendas, la seguridad física directamente; no es una violencia interpersonal sino de un entorno, y en ese sentido el concepto se enriquece cada vez más, se asumen nuevas dimensiones, deben incorporarse nuevos actores tanto en materia de prevención, básicamente en este último caso, como en políticas de mediano y largo plazo.

$\mathrm{CT} /$ Es interesante ver como el concepto de seguridad humana es un concepto integral; pero se vuelve necesario diferenciar los actores y las agendas en que esos temas se colocan. Por ejemplo, hay temas que corresponden a la agenda del desarrollo y temas que corresponden a las agendas de la seguridad propiamente ciudadana que involucra a otros actores. ¿Es cierto eso?

JC/ Sí, creo que el tema es ampliamente diverso y complejo; lo diverso lo vuelve cada vez más complejo. Si lo vemos en el ámbito de la seguridad ciudadana, el panorama ha cambiado bastante los últimos 15 años porque ya no sólo es la inseguridad que proviene de la convivencia cotidiana y de los problemas 
interpersonales, sino que es una inseguridad donde el móvil económico o la obtención de recursos vía actos delictivos ha cobrado un gran espacio. Aquí entra un nuevo actor que es el joven en las maras y pandillas, componente de los últimos tiempos que ha cobrado bastante peso, sobre todo en la vida cotidiana. Hace falta conocer cómo las maras y las pandillas en los barrios perjudican la vida del ciudadano, sobre todo con la extorsión económica. Ese es un tema bastante profundo porque estos jóvenes tienen redes de apoyo en sus comunidades, ya sea por temor a ser agredidos o porque también sus comunidades 0 algunos sectores de sus comunidades se benefician de su presencia. Y hay otro elemento u otro actor que a mi juicio, es el más peligroso porque vulnera directamente el Estado de Derecho, y es el crimen organizado. $O$ sea que si hablamos de seguridad ciudadana, es cierto que el crimen organizado pareciera que tiene una víctima muy definida; pero no necesariamente es víctima solamente la persona involucrada en este delito; hay otras víctimas y esto contribuye mucho a que la percepción de inseguridad y la desconfianza en la policía, se acentúe.

\section{CT/El fenómeno de la delincuencia y el fenómeno de la violencia, ¿van juntos o separados?}

$\mathrm{JC} /$ No van juntos necesariamente, pero generalmente sí; hay delitos que se comenten sin hacer uso de la violencia; pero hay delitos que implícitamente, si no se resuelven o si hay algún conflicto de interés, puede generar violencia. Antes los delincuentes tenían una forma de operación donde todavía se avergonzaban, y aprovechaban la oportunidad para entrar a una vivienda, asaltar a alguien, robarse un vehículo; pero últimamente hay un escalamiento en este delito y ya vemos que en muchos casos el robo va acompañado de homicidio y no solamente el robo de productos como vehículos, sino que robos inclusive de cuantías sumamente pequeñas. Lo que todavía la investigación policial no nos dice es si la víctima opuso resistencia o si sencillamente el victimario no quiere dejar testigo, porque cuando leemos los periódicos pareciera que en algunos casos el victimario no quiere dejar testigo y en otros es como una respuesta que se da cuando hay resistencia. Igual sucede con el crimen organizado; puede operar sin ejecutar actos de violencia si tienen cadenas de distribución, si el narcomenudeo les funciona; pero en el momento en que hay conflicto de intereses, o cuentas no saldadas, en ese momento las dirimen con sus propios códigos, porque como son ilícitos no pueden llevarlo a la justicia. Una deuda por drogas no la dirimen en un juzgado, la dirimen haciendo uso de la violencia. Pero hay encuestas en Tegucigalpa que nos arrojan que un porcentaje alto de delitos, no se ha ejecutado con violencia sino que nada más les arrebatan sus objetos. 
CT/ Esto nos lleva a otra pregunta: causas de la delincuencia. ¿Podemos hablar de un tipo de causas, de un conjunto de causas? ¿Qué explica el auge de la delincuencia en los últimos tiempos?

$\mathrm{JC} / \mathrm{Lo}$ que uno indaga por la lectura de la denuncia, por la lectura de la noticia, por el móvil que la policía identifica, vemos en el Observatorio de la Violencia que hay diversas causas: una, es la obtención directa de un objeto. Hay una cantidad de incidencia delictiva que tiene como móvil el robo de cuantías menores: un celular, una cartera. Luego encontramos el robo de vehículos, que ya tiene que ser otro móvil. Los delincuentes son personas que están organizadas, que pueden darle seguimiento a la víctima, que tienen un tiempo para dedicarse a eso. Esto funciona como una empresa, dan seguimiento a las actividades de sus víctimas: monitorean prensa para ver quienes venden vehículos, quienes rentan apartamentos, quienes venden casas y son llamados para extorsión. Eso implica una organización con empleados para esas funciones. Ahí estaríamos hablando ya de una actividad ilícita tendente a acumular riqueza.

Podemos encontrar otra de más bajo nivel que puede ser la sobrevivencia. Encontramos otros actos delictivos o actos de violencia y de criminalidad que tienen que ver con riñas interpersonales. Es bastante impresionante como en el país hay muy poca mediación de conflictos. Hay riñas entre familias por herencias y por disputas económicas, que terminan en un homicidio o una lesión. También encontramos la riñas por disputa de calle: personas en estado de ebriedad que empiezan a discutir. Hay poca propensión a la tolerancia, poca propensión a la discusión, a aceptar el argumento de la otra parte, y sobre todo en las ciudades que están muy congestionadas, eso está pasando mucho. La convivencia se encuentra bastante dañada en los vecindarios, amerita conocer más, darle seguimiento, y en esto los gobiernos locales podrían asumir un papel. Encontramos conflictos de barrios por manejo de los animales, o porque dañan bienes de algunas viviendas. Hay alguna cantidad de móviles, pero el que encontramos que está creciendo es el tipo de homicidio que tiene como modalidad el sicariato y que la policía lo define, de buenas a primeras, como ajuste de cuentas. A nosotros el concepto no nos parece como crimen organizado y ajuste de cuentas, porque como el nivel de impunidad es tanto en el país, hay personas que cualquier tipo de conflicto lo pueden resolver eliminando al adversario y eso realmente se está haciendo con mucha facilidad.

\section{CT/ ¿Se está estigmatizando a los pobres Julieta? ¿Se estigmatiza a los pobres cuando se piensa en ellos como delincuentes?}

$\mathrm{JC} /$ Creo que sí se estigmatiza, sobre todo por el tipo de delito. Yo creo que habría 
que diferenciar: es un hecho que los pobres están muriendo más, también son la mayoría en el país. Si uno ve la ocupación de las personas que están muriendo, son los empleados de más bajos ingresos y están ubicados en los barrios más pobres de las ciudades. Pero también se tiene un altísimo porcentaje de colonias pobres, entonces obviamente muere más gente de este sector. Los pobres están matando a los pobres, se están robando entre ellos mismos porque esas colonias están llenas de extorsión; ahí es donde se pagan los impuestos a los autobuses, ahí es donde mueren los conductores. Los homicidios en estas barriadas salen mucho en la prensa; pero si vemos quienes están en crimen organizado, estaríamos hablando de otros sectores; pueden vivir en barrios y en colonias con un nivel de pobreza, pero son personas que manejan recursos. Creo que en crimen organizado, en narcotráfico, en robo de vehículos, en asalto a furgones, es donde se da el mayor cúmulo de dinero que pueden reunir por estos ilícitos. El asalto a los carros en las carreteras sobre todo a las compañías distribuidoras, es objeto de bandas con un nivel de acumulación de recursos que les permite inclusive penetrar las estructuras del Estado. Sus ingresos les da para tanto, que son capaces de penetrar ya sea mediante intimidación o ya sea mediante captación.

\section{CT/ Soluciones a la inseguridad: ¿prevención o control? ¿Es una dicotomía o no debe ser así?}

$\mathrm{JC} /$ No debe ser una dicotomía. Ambas cosas son necesarias y tienen que ser simultáneas porque si hablamos de control ya estamos en el problema. No podemos hablar que la prevención va a funcionar con personas que están vinculadas al narcotráfico, porque ellos están acostumbrados a manejar un caudal de recursos que ningún programa de prevención les proveerá. Ellos ya tienen un ritmo, un estilo de vida, tienen redes y eso hay que controlarlo, hay que reprimirlo. Las leyes deberían ajustarse a los nuevos delitos globales; eso me parece importante. Pero también tenemos un contingente de personas que está creciendo, sobre todo jóvenes y menores que están en riesgo, que ahora están cometiendo faltas menores, hurtos menores; si no hay la posibilidad para que ellos puedan insertarse laboralmente, van a terminar en ilícitos mayores. Estos jóvenes muy tempranamente asumen roles de adultos: muy temprano son padres, muy temprano construyen familias, muy temprano se hacen responsables de otros y a veces muy temprano se hacen responsables de sus padres; eso requiere ingresos. Si unos logran estudios que les den un empleo a futuro, un empleo estable que les permita reproducirse con un nivel de dignidad, no van a estar en ilícitos; entonces, ambas cosas deben ser simultáneas. Hay que controlar y reprimir el delito, hay que reprimir estas bandas; pero también hay que trabajar en prevención. 


\section{$\mathrm{CT} /$ Niveles en que se puede, no solamente diseñar sino ejecutar una política de seguridad. El nivel nacional y el nivel municipal ¿complementarios?}

$\mathrm{JC} /$ Son complementarios. A nivel municipal hay un tema de seguridad muy importante que no hemos tocado: la seguridad en tránsito. Es realmente impresionante el número de víctimas anuales que hay en el país por hechos de tránsito, no solamente a nivel de muertes violentas sino también de lesionados. Sólo en Tegucigalpa el año 2007 hubo 222 muertes por hechos de tránsito y los que más mueren son los adultos mayores y los menores. En ese sentido se requieren también medidas de control y de prevención. Hay necesidad de que se delimiten los espacios, porque los gobiernos locales tienen la voluntad para ejecutar políticas de prevención, pero entran en contradicción con los intereses de la política nacional de tránsito, y eso se convierte en un problema. Debe haber relación y coordinación entre la política nacional y la local. Los gobiernos locales tienen potestad para trabajar en el ámbito de prevención, en el ámbito de la mediación de conflictos, en el ámbito de la cultura de la convivencia ciudadana, porque son problemas vinculados a los municipios; pero todavía no tenemos en el país municipios que estén comprometidos realmente con una política de prevención. Algunos han creado una tasa de impuesto municipal para seguridad y la pasan a la Policía para combustible, para patrullas, para que mejoren sus instalaciones físicas; pero realmente eso no es prevención. Tiene que haber cercanía entre la municipalidad o los gobiernos locales y el ciudadano. Pienso que todavía no se ha construido esa cercanía entre gobierno local y ciudadanía.

CT/ En materia de prevención, por lo general la prevención apunta al largo plazo ¿Podemos establecer intermediación entre ese largo plazo? Porque sentarnos a esperar 20 años para que fructifique una política de seguridad no es muy adecuado que digamos.....

$\mathrm{JC} /$ Yo pienso que deben y pueden haber acciones de muy corto plazo. Pueden haber políticas directamente orientadas a los menores en riesgo y los menores infractores. O sea, la política de poder reunir esos jóvenes en espacios para apoyarlos en su formación integral y de esta manera evitar que puedan llegar a ser victimarios. Son víctimas en este momento; esos jóvenes son asaltados, son niños que son violentados sexualmente, son niños que recogen dinero de algunas actividades como limpieza de vidrios y mendicidad; pero al mismo tiempo son asaltados por otros mayores. Entonces ahí estaríamos quitando de las ciudades un foco de inseguridad, de violencia actual y futura, y eso puede hacerse en un cortísimo plazo. El problema en el país es que todas las instituciones que se han creado a nivel del Estado, trabajan en políticas pero nadie quiere ejecutarlas. Todos 


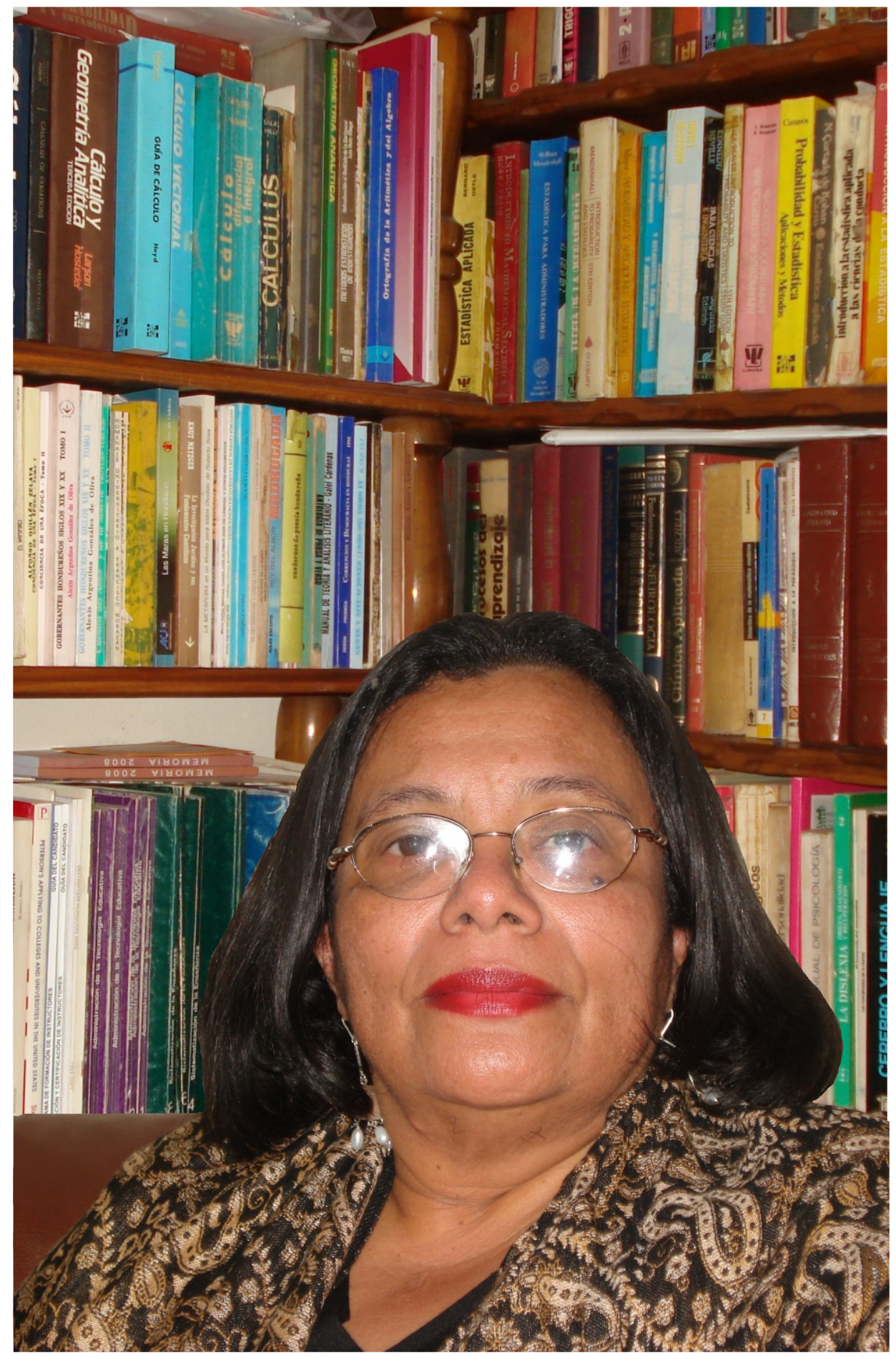


quieren el diseño de políticas, todos quieren ver quién ejecuta pero el Estado, en sí, está ejecutando muy poco; todas las instancias son rectoras de políticas, pero ¿quién ejecuta esas políticas? Lo que hace el Estado es muy precario. Deben haber medidas, como la que ha hecho el gobierno de Tegucigalpa con el centro histórico; podemos verlo en corto plazo: ha mejorado el centro histórico de la ciudad, y eso puede ampliarse en otras zonas; se pueden ir recuperando los espacios públicos, a mediano plazo o a corto plazo; pero pueden haber medidas de cortísimo plazo, que se vean ya los resultados, porque si no la gente se desencanta. Hay que poner medidas en el corto plazo, que se miren los resultados, e ir escalonando porque hay otras que requieren de mayores ingresos, mayores recursos y también de voluntad política.

\section{$\mathrm{CT} /$ Hay una concepción generalizada de que el problema de la inseguridad se debe a una crisis de valores: ¿Comparte ese criterio?}

$\mathrm{JC} /$ Yo creo que hay formas que pueden contribuir a que muy fácilmente las personas tengan acceso a bienes, a recursos, y, en la medida en que no haya costos para tener un nivel de comodidad, sin habérselo ganado por los canales legales, se puede convertir en un elemento multiplicador. Hay una oferta de servicios en la ciudad, en el país, y prácticamente en todo el mundo, que cada vez se convierte en necesidades sociales. Hay un desfase entre las necesidades sociales que están instaladas actualmente y los recursos legítimos para obtenerlas. Ese desfase entre las necesidades sociales que son necesidades inclusive de la familia y de los jóvenes -un celular, Internet en casa, cable- son necesidades de la época y eso incrementa la demanda en los padres. No hay esa construcción de ir valorando si la familia realmente puede hacerse de todo ese nivel de demandas sociales y sostenerlas en el tiempo. En la medida que no es posible, se puede optar a varias vías. Hay familias que multiplican su trabajo, que se buscan ingresos extras, que ponen ventas de comida en su casa o los padres empiezan a involucrarse en otro nivel de actividades y los ingresos no tienen origen en una actividad lícita. Si es fácil entrar en una actividad ilícita sin que haya costos y se ve el bienestar, se está asumiendo que si no le hago daño directo a nadie, si no sé a quién se vende la droga ni sé quién la consume, yo puedo vender drogas. Se va convirtiendo en una forma de vida. Por otro lado, llama la atención que la Policía no controla a quienes venden artículos robados. En una ciudad pequeña, ya deben tener mapeados los lugares donde venden artículos robados, porque hay personas que tienen como trabajo robar para ir a vender.

CT/ Ahí es donde entra en juego la sensación de impunidad, no van a ser castigados... 
$\mathrm{JC} / \mathrm{Si}$ la gente puede robar algo y no le pasa nada, lo vuelve hacer. Tiene temor en hacerlo pero lo hace, sigue sorteando. Si el robo le está dando ingresos y no tiene ningún costo, así resuelve su vida. Es como una cadena y hay una cantidad de lugares donde venden artículos usados, sin factura. ¿Quién los vende? La Policía debe tener los registros de estas tiendas, de estos negocios e intervenirlos. Hay medidas que podrían ir cerrando el círculo, pero que no se están tomando, no sé si porque hay problemas mayores que atender. Pero en esa medida hay un proceso de conformación de nuevas formas de vida y de justificación.

CT/ Dentro del Instituto (IUDPAS) un componente fundamental es el Observatorio de la Violencia... Con la experiencia que han acumulado ustedes en estudiar esencialmente víctimas de la violencia ¿qué ejes cree que se pueden desarrollar? De la experiencia que han acumulado ¿qué aspectos deben ser centrales en términos de una política de seguridad a nivel nacional o a nivel local?

$\mathrm{JC} /$ Tenemos una gran deuda en el Observatorio; debemos conocer el entorno de la víctima. No sabemos el nivel de orfandad que está dejando la violencia; quién está atendiendo a esos niños. Tenemos casos donde mueren los dos padres. Creemos que es crimen organizado porque muere el hombre acribillado el día jueves y el día lunes siguiente acribillan a su compañera. ¿Qué pasa con los lesionados? En los hospitales hay una cantidad de personas que entran graves y no sabemos qué pasa con ellas. Si mueren, salen por la morgue, por medicina forense; pero otros quedan lesionados de por vida, en silla de ruedas, con la columna dañada, etc. La carga es para la familia de esa víctima. Sentimos que hay un costo humano que no estamos viendo. Estamos viendo nada más a la víctima, al que murió; pero no vemos el lesionado, el impacto para la familia, el costo económico de tener un enfermo en un sistema de salud público, donde no hay medicinas suficientes; el costo de mantener, cuidar y dar medicamentos a un lisiado; costo que debe ser muy alto. Creo que hay algo que realmente es importante: cuando uno ve las cifras y ve la gente que está muriendo, tiene que saber que para que haya políticas y para que las leyes puedan mejorar, debe haber un mejor conocimiento de los hechos. No basta con contar y yo creo que el Estado nada más cuenta. Hay que saber el móvil. Nosotros estamos viendo en el norte del país, ciudades que van a terminar el año, si la tendencia del segundo semestre sigue, con 120 homicidios por cada 100 mil habitantes. En esos casos se debe declarar emergencia. El gobierno debería tener zonas identificadas donde tiene que ejecutar políticas con mucha presencia, con mucha fuerza. Se mezclan muchos elementos. En el norte del país nos informan que está llegando una gran cantidad de emigrantes colombianos y mexicanos. Obviamente estamos entre México y Colombia, países donde están los carteles 
más fuertes. ¿Qué está pasando en Honduras que se están trasladando mexicanos y colombianos? Ese debe ser un motivo de análisis de la inteligencia de la seguridad del país y de la inteligencia policial. ¿Por qué comienzan a flexibilizarse algunas medidas? Sentimos que el Estado no tiene la capacidad para responder; que ha sido rebasado. Esa es una conclusión a la que llegamos siempre que vemos las cifras. El Estado está rebasado en cuanto a estructuras de investigación, la policial; pero igual sentimos en cuanto al tema de fiscales y de jueces, porque estas dos instituciones, jueces y fiscales, no están protegidas. Entonces sentimos que para enfrentar los delitos del país, se requiere tener un Estado donde haya protección para sus funcionarios, por lo menos cuando hablamos de esta franja bastante amplia de crimen organizado que es grandísima. En el caso del Departamento de Cortés el $27 \%$ de los homicidios tienen esta modalidad de sicariato.

\section{CT/ ¿A quién le interesará información como la que usted ha planteado? Esta información uno la escucha y se preocupa, se angustia, ve negro el panorama del país. ¿Quién debe tomar medidas en base a esa información?}

$\mathrm{JC} /$ Nosotros hemos identificado cuatro sectores: los gobiernos locales, la Policía, la Secretaría de Seguridad y los parlamentarios. ¿Por qué los gobiernos locales? Porque en Tegucigalpa vemos muchísimos hechos de transito. Aquí hay que poner regulaciones, señalizar calles, poner advertencias, disminuir la velocidad en esos bulevares, hacer peatonales para adultos, no con gradas, con rampas. También hay problemas de convivencia, hay mucha desconfianza en el barrio. La convivencia en un barrio donde hay desconfianza tiene que ser muy difícil. Otro centro de atención es el Ministro de Seguridad y los directores de Policía de las 36 regionales. Esto lo hacemos para que la policía sepa que está siendo observada. Uno no tiene posibilidades de información como la tienen ellos. Nosotros les preguntamos si tienen mapeada a la gente que se dedica al robo en los pueblos, si tienen información de bandas, de gente que vende artículos robados. Que ellos se sientan exhibidos y comprometidos. Con los diputados también, porque ellos creen que mejorar la seguridad es nada más aumentar el presupuesto. Ellos tienen ese conflicto: más policías, más presupuesto. Para ellos ahí comienza y termina el problema de seguridad y con eso cumplen. Entonces tenemos la intención de hacerles ver que el problema es mucho más complejo que eso. Cuando invitamos a los diputados a nivel departamental, tenemos un poco más de eco que cuando se invitan a nivel general. Pareciera que a nivel general no asumen el tema como un problema que les compete directamente y lo dejan al Poder Ejecutivo. Yo siento que muchos de ellos en sus comunidades, saben quién es la gente que está metida a ilícitos. Ellos conocen y creo que es un problema que tratan de mantener a la distancia. Y también nosotros llevamos esta información a académicos, a ONGs, un 
poco para ir desmontando algunos estigmas como el tema de maras, para ir sensibilizando en el problema y para ver si motivamos investigaciones.

$\mathrm{CT} /$ Este es un punto central y obligado, dadas las características del Instituto que usted dirige y que por primera vez tenemos en nuestra Universidad un Instituto que va abordar el tema de seguridad en un contexto más amplio de democracia y paz. ¿Qué retos de investigación se plantean desde el Instituto y en base a la experiencia que han acumulado?

$\mathrm{JC} /$ Como Universidad tenemos retos en la investigación para ver tipologías, para conocer los problemas de la convivencia, los problemas que llevan a conflictos, para ayudar a buscar alternativas de solución. Institutos como el de Ciencias Jurídicas tendrían que ver esas coherencias legislativas 0 inconsistencias legislativas en materia de seguridad. Tiene que avanzarse también en ver y esto debe ser una responsabilidad nuestra el Estado de Derecho; si el ciudadano realmente siente que el Estado está cerca; si el Estado está protegiendo al ciudadano. La impunidad es un tema que hay que estudiarlo desde diferentes dimensiones, no en el plano jurídico, creo que no es nuestro ámbito, pero si tenemos que avanzar en ver esa eficiencia del Estado, porque hay zonas del país donde se imponen otros códigos, otras reglas del juego, otras formas de funcionamiento, que no son las del Estado. El Estado está perdiendo el control del territorio. Hay una disminución de su presencia, porque no solamente perjudica en el tema de seguridad; hay barrios donde los maestros se han retirado por el problema de inseguridad; hay colegios que ya no sacan sus alumnos de la jornada nocturna a las 10 de la noche, porque los buses no llegan; eso implica que quien está ganando los barrios es la delincuencia. Esos son los estudios que tenemos que hacer. Estamos perdiendo las ciudades, estamos perdiendo el país, la libertad de tránsito, las libertades se están perdiendo. Tenemos que hacer un estudio de las víctimas y de su entorno, el impacto en salud pública. Algo que está pasando y se conoce poco es el secuestro express; cómo la familia sobrevive el secuestro, a la extorsión. Se tiene que empezar a hablar de eso con más fluidez pero también estudiarlo, porque son temas que están perjudicando la calidad de vida de la familia; el impacto psicológico, el temor con que se vive después. Hay varias áreas: el punto de vista de la Sociología, de la Antropología Social, de la Psiquiatría, del Derecho. Realmente el tema es tan complejo que tiene que ser un enfoque multidisciplinario para poder tener los elementos para completar el rompecabezas. Nosotros apenas aportamos información; pero la misma observación que hacemos de los hechos, nos lleva a pensar en estas otras cosas que tienen que emplearse en la información. 
CT/ El panorama es sombrío en materia de inseguridad ¿qué se puede hacer para cambiar esa situación y ver con un poco más de esperanza, que las cosas no se van deteriorando como creemos?

$\mathrm{JC} /$ Algo que es central es el manejo de la política de seguridad en la Secretaría de Seguridad. Tiene que incluir la formación policial, la eficiencia y el control interno de la Policía, como una costumbre, porque hay poca confianza en la Policía. Hay muchos indicios de que algunos policías tienen poder y que están coludidos con el crimen, y hay mucho delito, sobre todo en el marco de la extorsión y los secuestros, y otros hechos de violencia, de crimen, donde puede mejorarse muchísimo con una mejor Policía. Un gobierno que quiera enfrentar un problema de lleno, debe tener estructuras, y la primera es la policial. Sin estructuras, ningún gobierno va a enfrentar los problemas. Tiene que tener la estructura policial, la estructura de la Fiscalía y la estructura de la Corte. Creo que todo lo demás que pueda hacer la sociedad civil no es lo central, porque lo que nos está agobiando la vida, es la percepción de inseguridad por los homicidios que uno ve en los barrios pobres, más en sectores vinculados con el crimen organizado. Pero hay una delincuencia que también está produciendo homicidios: los robos, los asaltos. Para enfrentar todo eso, el Estado requiere estructuras. Hay que hacer mucho trabajo para poder poner esto en escena. Creo que ese es el papel de la universidad: demostrar con los estudios que en Honduras se puede empezar a romper con lo que sucede. Uno sólo puede entender que el crimen organizado opera en regiones amplias porque está coludido con la autoridad.

CT/ Las perspectivas entonces, aunque no fueran alentadoras a nivel del país, sí lo son a nivel del Instituto porque tiene unos grandes retos temáticos a desarrollar para llegar a conocer mejor el problema más allá de la percepción de la ciudadanía, porque eso se queda en un nivel bastante subjetivo. El hecho de utilizar métodos científicos, técnicas adecuadas para investigar el problema, significa que estamos dando un gran paso adelante, particularmente proporcionando la información como herramienta de políticas adecuadas.

$\mathrm{JC} /$ Creo que eso es correcto y nosotros lo que tenemos que empezar a pensar es cómo trasladamos eso al Estado (análisis, resultados, propuestas) y como instituto generar información obtenida con rigurosidad metodológica y, sobre todo, altamente confiable, lo que le permitiría al Estado una mejor calidad en la toma de decisiones y en la elaboración de políticas adecuadas a las necesidades de nuestro país. 